\title{
UK mouth cancer cases reach record high
}

\author{
New cases of mouth cancer in the UK have risen to a record high, according \\ to the findings of a new report.
}

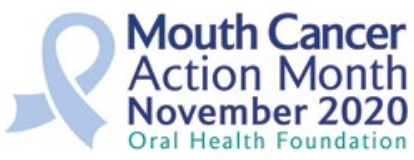

Figures collected by the Oral Health Foundation show that 8,722 people in the UK were diagnosed with the disease last year, increasing by $97 \%$ since 2000 . Mouth cancer cases in the UK have soared for the eleventh year in a row and have more than doubled within the last generation.

The findings are part of the charity's new State of Mouth Cancer UK Report 2020/21 ${ }^{1}$ and have been released to coincide with November's Mouth Cancer Action Month.

Dr Nigel Carter OBE, Chief Executive of the Oral Health Foundation, believes with mouth cancer cases continuing to rise, more must be done to raise awareness of the disease.

Dr Carter said: 'While many cancers are seeing a reduction in the number of people affected, mouth cancer is one of very few that is sadly going the other way. Established risk factors like smoking and excessive alcohol have been joined by emerging causes like

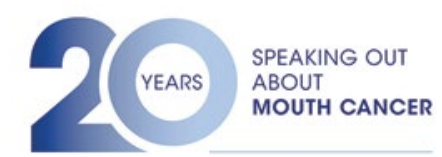

the human papillomavirus (HPV). This has changed the profile of the disease quite considerably over recent years and mouth cancer can now affect anybody.

'The disease can have a devastating and lasting effect on a person's life. It can change how somebody speaks, it makes eating and drinking more difficult, and often leads to changes to a person's physical appearance. Because of this, it also takes a heavy toll on a person's mental health too.

'One of the biggest challenges we face regarding mouth cancer is how little educational support it receives from government and public health bodies. As part of Mouth Cancer Action Month, we are appealing for your help to improve awareness of the disease so that more people are able to recognise the early warning signs.'

Statistics from governing health bodies across the UK show around two-in-three
(67\%) mouth cancers are recorded in men while three-in-four (78\%) are in the over $55 \mathrm{~s}$.

Mouth cancer is most likely to occur in the tongue, contributing to more than one-inthree (34\%) cases. Mouth cancer can also appear in the tonsils, the roof and floor of the mouth, lips and gums.

The early warning signs of the disease include mouth ulcers that do not heal within three weeks, red or white patches in the mouth, or unusual lumps and swellings. Persistent hoarseness could also be a symptom.

The Oral Health Foundation has created a range of digital resources for you to display in waiting rooms, share via email and practice newsletters, and on social media. All of these can be accessed from the Mouth Cancer Action Month digital toolkit, which you can download at https://bit.ly/36JQ9GX.

By registering your support at www. mouthcancer.org, the Oral Health Foundation will send you a free poster to display in your practice, and an enamel Blue Ribbon Badge.

\section{Reference}

1. Oral Health Foundation. State of Mouth Cancer UK Report 2020/21. November 2020. Available at: https://www. dentalhealth.org/thestateofmouthcancer (accessed November 2020).

\section{GDC publishes 2019 fitness to practise statistics}

The General Dental Council (GDC) has published several reports which provide statistics and examples of fitness to practise case handling undertaken during 2019.

The statistical report provides a quantitative picture of fitness to practise in 2019. In addition, the regulator has also published six short insight reports covering decisions at the initial assessment stage for quarters three and four of 2019 , including spotlight reports on concerns relating to consent and record keeping.

The reports show that of all the concerns received in 2019 , only $36 \%$ made it to a case examiner - the first stage at which a sanction may be imposed on a dental professional. The reports also reveal a further year-on-year increase in concerns raised by dental professionals, from $10 \%$ to $13 \%$ of the total, including 'blue on blue' cases - separate to those which are categorised as 'whistleblowing' by professionals.

Executive Director of Fitness to Practise Transition at the GDC, John Cullinane, said: 'What is clear from these reports is that the large majority of concerns received by the GDC are assessed and completed without sanction, but they also highlight that early engagement in the process will typically end in a smoother resolution to any concern that's raised, which ultimately must be in everyone's interests. The increase in referrals by registrants also highlights an important issue; while we of course need to avoid any discouragement of whistleblowing or the raising of serious issues affecting patient safety or public confidence, matters such as employment disputes or grievances which we are seeing on an increasing basis - are not for the regulator to investigate or resolve.

'There's some really useful insights to be gained here for dental professionals, particularly from the case examples in the short reports, so I'd encourage everyone to take a look'

The full reports are available to read on www.gdc-uk.org.

The GDC has also announced that the annual retention fee $(A R F)$ will remain unchanged for 2021, due to the significant uncertainty thrown up by COVID-19 and Brexit'. 